\title{
A theory on the role of $\pi$-electrons of docosahexaenoic acid in brain function ${ }^{\star}$ The six methylene-interrupted double bonds and the precision of neural signaling
}

\author{
Crawford $\mathrm{MA}^{1,{ }^{*}}$, Thabet $\mathrm{M}^{1}$, Wang $\mathrm{Y}^{1}$, Broadhurst $\mathrm{CL}^{2}$ and Schmidt $\mathrm{WF}^{2}$ \\ ${ }^{1}$ Institute of Brain Chemistry and Human Nutrition, and Department of Cancer and Surgery, Chelsea and Westminster Hospital Campus \\ of Imperial College, London, Room H3,34, 369 Fulham Road, SW10 9NH London, UK \\ ${ }^{2}$ United States Department of Agriculture, Agricultural Research Service, Beltsville, MD, USA
}

Received 16 November 2017 - Accepted 12 February 2018

\begin{abstract}
Background: Docosahexaenoic acid (DHA) has been the dominant acyl component of the membrane phosphoglycerides in neural signaling systems since the origin of the eukaryotes. In this paper, we propose, this extreme conservation, is explained by its special electrical properties. Based on the Pauli Exclusion Principle we offer an explanation on how its six methylene interrupted double-bonds provide a special arrangement of $\pi$-electrons that offer an absolute control for the precision of the energy of the signal. Precision is not explained by standard concepts of ion movement or synaptic strengthening by enhanced protein synthesis. Yet precision is essential to visual acuity, truthful recall and the exercise of a dedicated neural pathway. Concept: Synaptic membranes have been shown to actively incorporate DHA with a high degree of selectivity. During a learning process, this biomagnification will increase the proportion of membrane DHA with two consequential neuronal and synaptic enhancements which build into a David Marr type model of the real world: DHA induced gene expression resulting in enhanced protein synthesis; increased density of $\pi$-electrons which could provide memory blocks and provide for the preferential flow of a current in neural pathways. Proposal: Both the above imply memory from synaptic strengthening. We propose memory is achieved by the activation of neuronal synaptic activation with synaptic turnover resulting in enhanced membrane DHA, which in turn induces gene expression, protein synthesis and $\pi$ electron density. Repetition amplifies the process activating synapses, which form a matrix representing the memory. The electro-chemical potentials then fire the electrons as electromagnetic waves via the six methylene interrupted double bonds. These allow transmission at a specific energy level based on their quantum mechanical properties providing the precision required for faithful recall. It is difficult to conceive of protein synthesis alone providing for precision. Using the principle of the dual properties of photons and electrons we develop the idea of complex wave patterns representing the visual or auditory fields. These are likely to be noncomputable. We suggest that harmonization of the electromagnetic waves can result in cohesion explaining recall and associations. The cohesion of electromagnetic flow leads to a surge above the resting level, which is recognized by the brain as, demonstrated in artificial, electrical stimulus during neurosurgery.
\end{abstract}

Keywords: chaos theory / docosahexaenoic acid / $\pi$-electrons / signal precision / quantum mechanics / memory / cognition / perception

Résumé - Une théorie sur le rôle des électrons $\pi$ de l'acide docosahexaénoïque dans la fonction cérébrale. Les six doubles liaisons interrompues par un groupe méthylène et la précision de la signalisation neuronale. Introduction: Depuis l'origine des eucaryotes, l'acide docosahexaénoïque (DHA) est l'acide gras majoritaire des phosphoglycérides des membranes dans les systèmes neuronaux de signalisation. Dans cet article nous proposons d'expliquer cette préservation du DHA par ses propriétés électriques spécifiques. À partir du «Principe d'Exclusion de Pauli », nous proposons une explication sur la manière dont les six double-liaisons successives du DHA, interrompues par un groupement méthylène,

\footnotetext{
^ The 2015 Chevreul Medal lecture, Lipids and Brain III Conference

*Correspondence: michael. crawford@imperial . ac . uk
} 
fournissent une disposition spécifique des électrons $\pi$ qui offre un contrôle absolu de la précision du signal énergétique. Cette précision ne peut être expliquée par les concepts anciens basés sur les échanges ioniques ou sur un renforcement des synapses via une synthèse accrue de protéines. Pourtant, la précision est essentielle à l'acuité visuelle, à une mémoire fidèle et à la mise en œuvre d'une voie neurale dédiée, telle que décrite dans la partie I. Concept : Il a été démontré que les membranes synaptiques incorporent activement du DHA avec un haut degré de sélectivité. Au cours d'un processus d'apprentissage, cette «bioamplification» va accroître la proportion de DHA dans les membranes avec, en conséquence, deux augmentations - neuronale et synaptique - selon un modèle de type «David Marr», du nom du neuroscientifique anglais qui a cofondé le champ des neurosciences computationnelles: l'expression de gènes induite par le DHA conduit à une augmentation de la synthèse protéique; la densité accrue des électrons $\pi$ pourrait apporter des «blocs de mémoire» et permettre un flux préférentiel de courant dans les voies neuronales. Proposition : Les deux propositions précédentes impliquent une mémorisation à partir du renforcement synaptique. Nous proposons que la mémoire se développe à partir d'une activation synaptique neuronale avec un turnover synaptique entraînant l'enrichissement de la membrane en DHA, qui induit à son tour l'expression des gènes, la synthèse des protéines et la densité en électrons $\pi$. Les phénomènes de répétitions amplifient ce processus d'activation des synapses qui forment alors la matrice représentative de la mémoire. Les potentiels électrochimiques excitent les électrons sous forme d'ondes électromagnétiques via les 6 double-liaisons interrompues par le groupe méthylène. Ceux-ci permettent une transmission à un niveau d'énergie spécifique reposant sur leurs propriétés de mécanique quantique, fournissant ainsi la précision requise pour une mémorisation fidèle. Encore une fois, il est difficile d'imaginer que cette précision puisse être obtenue à partie d'une simple synthèse de protéines. En utilisant le principe des propriétés des photons et des électrons, nous développons l'idée de motifs d'ondes complexes représentant les champs visuels ou auditifs. Ceux-ci sont susceptibles d'être «non-calculables» (noncomputables). Et nous suggérons que l'harmonisation des ondes électromagnétiques peut entraîner une cohésion explicitant la mémorisation et les associations d'idées. La cohésion du flux électromagnétique conduit à l'apparition de pics au-dessus du niveau de repos, qui peuvent être reconnus par le cerveau, comme cela a pu être démontré par les stimuli électriques artificiels en neurochirurgie.

Mots clés : théorie du chaos / DHA, électrons $\pi$ / précision du signal / mécanique quantique / mémoire / cognition / perception

"Imagination is more important than knowledge. For knowledge is limited to all we now know and understand, while imagination embraces the entire world, and all there ever will be to know and understand."

Albert Einstein

\section{Introduction}

\subsection{Docosahexaenoic acid}

The aim of this paper is to discuss a possible function of the electrons in brain function. We have selectively focused on the possible role of the $\pi$-electrons of all-cis-docosa4,7,10,13,16,19-hexa-enoic acid (DHA, 22:6 $\omega 3$, or cervonic acid) because it so densely populates the neural signaling membranes and has done so, since the origin of nervous system and the brain some $500-600$ mya. This extreme conservation is despite the fact that there are two almost identical molecules differing by only one double bond, yet neither were used (Fig. 1). The implication is that the full six methylene interrupted double bond sequence is critical and may well have some special electrical property (Bloom et al., 1999).

\subsection{The accepted view}

Concepts of brain function were the topic of Part I. Notably, the 2016 Grete Lundbeck European Brain Research Foundation Prize for Timothy Bliss, Graham Collingridge \&
Richard Morris was given for their ground-breaking research "which showed how the connections - the synapses - between brain cells in the hippocampus can be strengthened through repeated stimulation" . This prize provides confidence that the strengthening of synapses with protein synthesis is the now accepted view on the establishment of memory. It is however, difficult to see how protein synthesis could provide for the absolute precision required for neural signaling and truthful photo-reception, executive action or recall.

The job of the protein is, we suggest, to provide for the prodigious energy consumption by the brain and the maintenance of its structures. The photo-receptor is the synapse for the brain with the outside, visual world. Its cell body is densely packed with mitochondria. The receptor segment is made of DHA rich membranes arranged in discs which house the light sensitive rhodopsin, the G-proteincoupled-receptor.

Precision of the signal whether in photo-transduction or synaptic transmission, is essential for true function. If two photoreceptors responded differently to the same energy (wavelength), then visual acuity would be lost and memories blurred: vison would blurred and memory would wander or fail.

We wish to offer a suggestion as to how such precision might be achieved. We base our hypothesis on the fact that the brain is largely made of a highly-specialized fat, the DHA

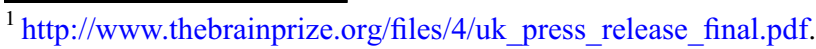




\section{снз $/ V^{=} V^{=} V^{=} V^{=} V^{=}$Мсоон DPA n-6 $\Delta-19$ double bond missing}

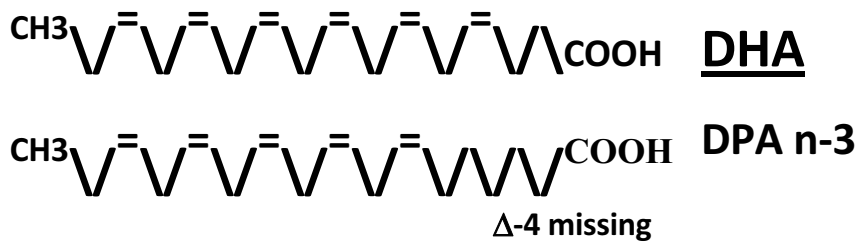

DPA $n-3$ THE $\triangle-4$ DOUBLE BOND IS OMITTED

DPA $n-6$ THE $\Delta-19$ DOUBLE BOND IS MISSING

Fig. 1. DHA: Although the n-3 DPA is a precursor for DHA neither DPA replaced DHA in 500 million years of evolution. The full sequence of 6 methylene interrupted double bonds is likely the key to the absolute conservation of DHA in neuronal signalling membranes throughout animal evolution.

component of which, provides for a quantum mechanical solution to the problem of signal precision.

Evidence that learning was indeed associated with actual increase in size of a region of the brain was provided by the MRI study of the brains of London Black Cab Taxi drivers. London is a large city. It has many small roads, mews and lanes. Learning the streets of London and the best routes takes several years for an aspiring taxi driver to acquire what is called the knowledge. "In those who qualified, acquisition of an internal spatial representation of London was associated with a selective increase in gray matter (GM) volume in their posterior hippocampi and concomitant changes to their memory profile. No structural brain changes were observed in trainees who failed to qualify or control participants" (Woollett and Maguire, 2011).

A recent study of contemplative mental training of different practice types targeting attentional, socio-affective, or socio-cognitive abilities of 300 volunteers provides further evidence of a material increase in a regional brain structures in response to learning. MRI scans, after a 3-month training period, showed that parts of the brain cortex relevant to the trained skill had grown thicker (Valk et al., 2017).

Merzenich et al. (2014) described degree of plasticity exhibited by sensory circuits. Reorganization in the somatosensory and auditory cortexes can occur even in adulthood. Hence, acquired learning and the training of organs like the hand can have powerful effects on the cerebral cortex (Merzenich et al., 2014).

These and other studies make it evident that learning does involve new structures and hence the involvement of proteins, RNA and DNA. However, as the structures involved are rich in DHA it also means an increase in the $\pi$-electron density from the methylene interrupted double bonds of increased DHA, which largely resides in the bi-layer lipid membrane.

The cell membrane is comprised of a bi-layer with the conducting head groups in the water phase on both inner and outer sides and the fatty acids in the middle. Hence, you have two conductors separated by an insulator, which is the classical description of a capacitator. Here we have an insight into the potential for rigid control of the signal energy.

\subsection{What about the electrons?}

We accept the classical principle of ion movements. It is however difficult to see how that provides the exquisite precision essential to the truth of neuronal signaling, nor to believe that the sea of $\pi$-electrons known to exist in the photoreceptor, neurons and synaptic signaling membranes, just sit there unaffected by the potential differences created by the ionic interchanges.

Moreover, electrons have properties relevant to signaling and indeed the evident electrical properties of the brain. Communication is many times faster than the movement of potassium, calcium and especially sodium ions with their shells of water of hydration. By contrast, an electric charge effectively emits a Coulomb electric field, which propagates radially at the speed of light. A current emits an Ampèrian magnetic field again at the speed of light, electron entanglement is instantaneous and so even faster. Moreover, the field can induce electron flow in another conductor which is the basis of a dynamo. Those electrons can move in and out of their outer energy level many millions of times a second is known from the construction of atomic clocks. An important consideration is the dual properties of an electron which can behave as a particle and a wave. Einstein gained the Nobel Prize for the photo-electric effect: the interchangeability of a photon and an electron.

In this paper, we take the protein and ionic evidence as accepted. We however, offer a different view of brain function based on electrons and specifically $\pi$-electrons. We suggest, the energy involved in the ionic movements provides the potential differences for the flow of electrons without which the brain is dead. That flow we propose is chaotic until such time as it is directed or flows down a pathway.

Neurons and synapses have membranes rich in DHA, which has six methylene, interrupted, double bonds. Their $\pi$ electrons are in the resistor region of the membrane bi-layer, each pair, separated by a - $\mathrm{CH} 2-$ group and consequently localized. Under specific conditions, they can be de-localized and a current (electron waves) can flow at a quantized energy level, which we propose is the key to precision of the signal.

We like to think of the David Marr images in the brain as wave forms of multi-dimensional, electro-magnetic matrices of synapses and cells. The synapses are an effective sea of DHA's $\pi$-electrons. Although the neurons themselves are doubtless participants in information flow, the capability of forming matrices representing the real world is several orders of magnitude greater in the synapses compared to the neurons themselves. The neurons are responsible for maintaining axons and synapses. Hence, there is also the possibility that neuronal DNA stores epigenetic information, which can maintain synaptic, memory data feed-back. The purpose of this paper however, is to focus on the quantum mechanical principles which would allow the $\pi$-electrons of DHA to form cloud like Marr images and specially to provide for precision of the signals and neural pathways.

\subsection{The law of induction}

Our thesis is that the brain is a machine governed by quantum mechanical principles. Our thesis starts with the 
Maxwell-Faraday's law of induction. As discussed in Part I, the operation of induction at the macro level can be taken to operate at the micro level of the neural circuits. We propose that electromagnetic induction is the operating principle behind associations within the neural circuitry. There is however, a fundamental difference. The current cannot be free flowing as in a dynamo. It needs to be constrained to operate at a fixed energy level as in semi-conduction to provide precision for the signal. Without precision, the execution of a neural circuit would blur and lose meaning.

In the companion paper 1 , we reviewed some of the background theories of brain function. Here, we present our theory of how the brain works based on electron movement rather than protein synthesis (Crawford et al., 2018). We do not dispute the role of the proteins synaptic strengthening and include that as part of our thesis. Nor do we dispute the ion movements, which generate potential differences, as these are likely the motive force for electron movement. However, we suggest the thesis, that it is electron behaviour governed by quantum mechanical principles, that does the work of signalling. The classical movement of ions is accepted but viewed as the creator of potential differences that stir the electrons into action.

\subsection{Properties of an electron}

Hydrogen and carbon, are the two most common elements in biology. As we discussed in Part I, electrons are considered to be in orbit around the positive nuclei of an atom. In organic chemistry, two carbons are considered to be joined by sharing a pair of electrons to form a sigma bond. Hydrogen is joined to carbon by sharing one electron. Two adjacent carbons can share a second pair of electrons with the two outer orbitals overlapping making a double bond around both carbon atoms with the $\pi$-electrons.

The Pauli Exclusion Principle states that no two electrons in the same orbit, can have the same values of the four quantum numbers: $\mathrm{n}$, the principal quantum number, $\ell$, the angular momentum quantum number, $\mathrm{m} \ell$, the magnetic quantum number, and $\mathrm{ms}$, the spin quantum number.

In some respects, electrons, which are fermions may be considered as identical. To solve their so-called identity we need to use a linear combination of the two possibilities. However, it is not possible to determine which electron is in which state. The wave function for the state in which both states "a" and "b" are occupied by the electrons can be written (Valk et al., 2017) for an electron:

$$
\Psi=\Psi_{1}(a) \Psi_{2}(b)-\Psi_{1}(b) \Psi_{2}(a),
$$

where $\Psi$ is the probability that both states are occupied by electrons 1 and 2 . The Pauli exclusion principle means that:

$$
\Psi=\Psi_{1}(a) \Psi_{2}(a)-\Psi_{2}(b) \Psi_{l}(b) \text { is impossible. }
$$

The confinement of an electron in a box requires energy, the smaller the box the greater the energy. However, there is no such thing as a box at the atomic scale. There are no walls. We only have energy fields. This concept is relevant to the way we propose electrons perform feats of memory and associations.
High energy scattering from electrons shows no "size" of the electron down to a resolution of about $10^{-3}$ fermis, and at that size a preposterously high spin rate of some $10^{32} \mathrm{radian} / \mathrm{s}$ would be required to match the observed angular momentum (Valk et al., 2017). It is like dealing with ghosts which is another way of looking at the Heisenberg uncertainty principle.

We suggest here that Clarke-Maxwell induction provides the means for electron communication within the brain. The Clarke-Maxwell induction would at the atomic level of neural function be expressed as harmonic relationships between different parts of say a memory creating a cohesion of enhanced electro-magnetic energy that is recognized by the brain.

\subsection{Chaos theory and determinism}

In principle, our thesis is like the harmonization of sound waves across space-time and the property of electro-magnetic waves to generate electricity. It is essentially a Faraday-ClarkMaxwell induction within the circuits of the brain. Memory is achieved by repetition, which strengthens the synapses creating a David Marr (Marr, 1982; Willshaw et al., 1971) type model within the brain. Any Marr type model of the real world would consist of a complex of electromagnetic wave forms or packets, stored by the repeated enhancement of DHA. Re-incorporation of DHA during activation turnover, results in increased membrane density of DHA, which turns on protein synthesis and enriches the $\pi$ electron density of the neurons and synapses.

In the case considered by Clark-Maxwell, he was describing the effect of a material conducting an electromagnetic flow inducing an electron flow in a second conductor. We propose a similar effect in the quantum world except, as we will explain, the special arrangement of the $\pi$-electrons in DHA permits control of the energy leading to precision of the signal.

Let us suppose the brain is consistently full of chaotic electron flows. Once the chaotic wave has become deterministic down a preferential path of $\pi$-electrons, a starter electric field is created. The starter field can then, harmonise with a wave identity linking one with the other to induce a summation of the electromagnetic current flow.

An image as for example, recording of a person's face, a flower, a poem or a song, will be composed of many different wave characteristics (see Fig. 6) in a multi-dimensional matrix of enhanced $\pi$-electron density. These will be recorded in the cluster of neurons-synapses, which has been strengthened by persistent looking, exercise or repeated encounters.

We need a name to identify with the image. A name of a face, would enter the brain's circuitry from the auditory route. The name and visual image will usually be simultaneous. For successful recall, there must be a cohesion of the wave properties of the person's face, created from the visual input, and those of the name simultaneously entering the brain through the auditory route. The Marr models need not be in the same location within the brain, and indeed, may even be able to move. All that is required is that within the wave forms of the face for example, a harmonic induction of the "name" is activated when the face is seen.

Specificity for recall or association, would be provided by the harmonic cohesion of wave forms. The summation of the 
electro-magnetic energies breaching the silent level of the chaos is felt by the brain: the brain has no pain receptors but feels electricity - the electron surge is perceived as recognition. Conversely, if the face is sufficiently well known, the mention or recall of the name may also induce an image of the face in the mind. The complexity of the cohesion of wave form for the face and name would likely be multi-dimensional, analogue rather than digital. These are not stored as $0 \mathrm{~s}$ and $1 \mathrm{~s}$. They are formed as shapes made up of wave form clusters with specificity derived from the cluster of wave properties.

\subsubsection{A thought occurred to me on the way to the market}

A memory module in the brain could be activated by sensory input or possibly by spontaneous electrical input from the chaotic flow of electron waves activating a memory locus. This would give rise to a spontaneous thought popping into consciousness as happens virtually all the time we are awake and likely, haphazardly with dreaming during REM sleep.

Scholes et al. (2017), described a phenomenon in photosynthesis of plants, which has similarities with our proposal for the brain. They found the unambiguous signature of non-classicality is given by a negative joint probability of finding the chromophores with certain relative positions and momenta. In classical physics, probability distributions are always positive.

Our proposal is similar to the cohesion where Scholes et al. (2017) describe "coherence phenomena arise from interference, or the addition, of wave-like amplitudes with fixed phase differences". This principle would apply in our model to explain memory, recall and much else.

Our proposal for brain function is an example of coherence phenomena resulting from the addition, of wave-like amplitudes with fixed phase differences. When a single string is struck on a piano, harp or other musical instrument the sonic waves will cause other strings in harmonic range to vibrate or sing. If that can happen with sound waves, then surely the flux of electron waves will similarly perform. And of course, we know they do as it is the basis of generating electricity. We will later address the dual properties of electrons to help explain our reasoning for their behaviour within the brain as electromagnetic wave forms providing the security of signal precision.

\section{Supporting evidence}

\subsection{Four notable pieces of evidence which help support our view}

\subsubsection{Our photo-receptors face the wrong way}

Our thesis depends on considering the electrons primarily as waves. There is a situation in photoreception which at first appears as counterintuitive. The photoreceptor faces away from the light and faces the retinal pigment endothelium with its cell body towards the incoming light. That is, it is not facing towards the incoming light but away from it. Effectively it is upside down. We have proposed the reason for this apparent anomaly, is that the forest of back ends facing the light ensures the photons act as waves rather than particles, analogous with Young's double slit experiment (Crawford et al., 2013).

Photons behaving as a wave makes sense. In the classical view of photoreception, the photon must strike a single $\pi$-electron located in orbit around a specific 11-cis double bond in a molecule of retinal in rhodopsin, to initiate the signaling process. As a particle, a photon is of the tiniest. Travelling at the speed of light a photon particle is required to hit an electron, also tiny, and itself travelling at a great speed in a very specific location in the middle of a protein. It is expected to hit this one electron and only this one, to transfer energy with sufficient power to make this specific electron, jump out of its orbit. Following its re-capture, the double bond between the carbons falls in to the trans-position resulting in a physical change in shape to become all trans retinal which then initiates the signaling process.

The probability of a photon energizing a very specifically localized $\pi$ electron would be far greater as a wave than as a particle. It can also be argued that there are several thousand rhodopsin molecules on a photoreceptor disc and several thousand discs in the outer rod segment which also improves the chances of a hit. Nonetheless, it seems it is the tip that sloughs off with use. The photon as a wave transforms the probability into a certainty. The conclusion is that the system works by processing visual range and electromagnetic waves rather than particles and that is why the photo-receptor is upside down.

\subsubsection{A high degree of selectivity is exercised for DHA during neural membrane synthesis and activation}

The activation of the photo receptor and the synapse leads to turnover and resynthesis (Rodriguez de Turco et al., 1999). Hiramitsu Suzuki showed how synapses incorporate docosahexaenoic acid (DHA) in preference to similar fatty acids with a high degree of selectivity and specificity (Suzuki et al., 1997). When the synapses turn over following use (e.g., in learning) they will re-incorporate DHA and each time, do so at higher concentration levels than before. This is the biomagnification effect we reported several years ago (Crawford et al., 1976) (see Fig. 2). Each time DHA is incorporated into the membrane it does so at enhanced levels because of preferential selection of DHA compared to other similar fatty acids, shown by Suzuki and well established as a general principle in lipid biology.

In the photoreceptor, turnover maintains DHA at the highest level of full saturation for optimum function. Virtually every phosphoglyceride molecule contains DHA in the SN2 position and some also in SN1. The photoreceptor cannot afford to learn; it must report fully and faithfully from first light.

In the synapse, the DHA is present at a much lower concentration. The synapses by contrast, learn through DHA biomagnification. The synapse has room for increasing or indeed decreasing its DHA membrane level which is what we propose is at the root of learning and memory and forgetfulness.

\subsubsection{DHA incorporation stimulates gene expression and protein synthesis}

Synaptic enhancement by protein synthesis as an explanation for memory is the generally accepted view and was the basis of the 2016 Brain Prize of the Grete Lundbeck European Brain Research Foundation. Tim Bliss, Graham Collingridge and Richard Morris collectively revealed how 
The biomagnification of DHA from food to the photoreceptor. At each interface the phosphoglyceridesare broken down and re-synthesised with a preferential re-incorporation of DHA.

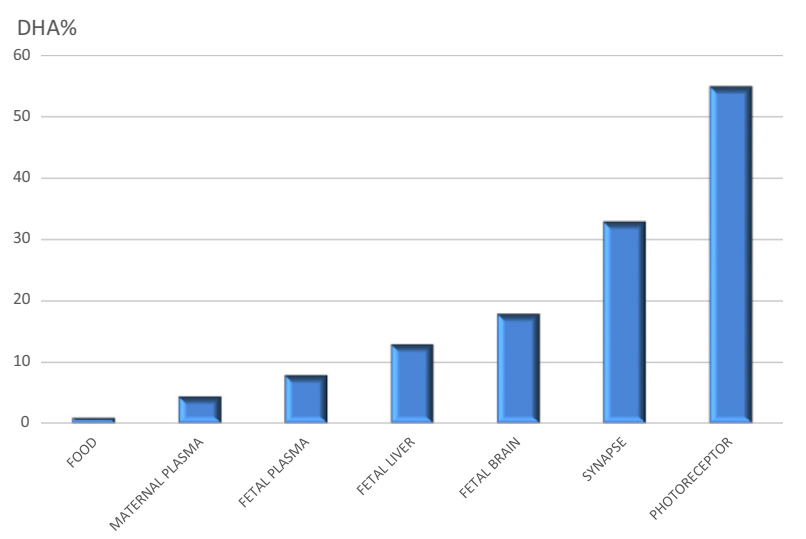

Fig. 2. Biomagnification: At each interface the hydrolysis and resynthesis of DHA containing phosphoglycerides results in the selective increase in proportion of DHA containing phosphoglycerides. This process was described as bio-magnification (Suzuki et al., 1997).

strengthened connections between synapses can store our memories. DHA has been shown to act as a ligand for nuclear receptors and activate the expression of several neural genes (Marr, 1982; Chawla et al., 2001). The high degree of selectivity for incorporation of DHA during turnover would both increase synaptic protein and the density of the $\pi$ electrons. We propose that the enhancement of protein synthesis is the byproduct of stoichiometric increase in DHA ligand activity with the repetitive DHA enrichment involved in learning. Synaptic activation will involve the highly specific re-incorporation of DHA into the synapse as shown by Suzuki et al. (1997). Increased synaptic DHA has two effects:

- DHA activates gene expression and protein synthesis (Kitajka et al., 2004);

- increases the $\pi$-electron density.

Thus strengthening a pathway as classically linked to memory storage.

Our proposal is the same as the conventional interpretation of synaptic strengthening by protein synthesis as described by Bliss, Collingridge and Morris ${ }^{2}$. We add to that scheme the idea that it is the lipid and electrons, not the protein which is the basis of memory and recall. The protein synthesis contributes to synaptic strengthening but is turned on by the known function of DHA in activating many neural genes.

Moreover, synaptic strengthening by protein synthesis, by itself, does not provide for the precision required for truthful signaling. We will offer a solution to this problem with a quantum mechanical description which provides for close to absolute precision of the signal not described previously but essential for making sense of sensory input and truthful recall.

\footnotetext{
${ }^{2} 2016$ Brain Prize, the Grete Lundbeck European Brain Research Foundation.
}

\subsubsection{Some $26 \%$ of energy use is for recycling fatty acids} into neural membranes

There is an astonishing but little-known fact supporting the importance of fatty acid recycling in the brain. Purdon and Rapoport (2007) have estimated that an astounding $26 \%$ of all the energy used by the brain is used for re-esterification of fatty acids. That is $26 \%$ of the prodigious energy use by the brain is being used to recycle the fatty acids into the membrane phosphoglycerides. With DHA as the major acyl component of synaptic and neuronal signaling membranes, much of this energy will be used in DHA turnover and re-incorporation. Such a large amount of energy together with the high selectivity for DHA, indicates that DHA recycling in the membrane is likely to be a major component of brain function.

As referred to above, support for this hypothesis also comes from work on energy transfer in light-harvesting macromolecules, which was shown to be assisted by specific vibrational motions of the chromophores. Alexanda OlayaCastro (UCL Physics \& Astronomy), supervisor and co-author of the research said. "We found that the properties of some of the chromophore vibrations that assist energy transfer during photosynthesis can never be described with classical laws, and moreover, this non-classical behaviour enhances the efficiency of the energy transfer." (O'Reilly and Olaya-Castro, 2014)

\subsection{Long term memory}

We can offer an answer to the question on the longevity of long-term memory. It would be the consequence of the continuous, yet chaotic, electromagnetic flow in the brain, maintaining the enhanced synaptic models - our memories. In the awake state, the brain is occupied with millions if not billions of signals. During sleep, these are shut out or toned down. Perhaps this is the time when deep memories are penetrated and re-strengthened. Loss of DHA with time would weaken an unused model or pathway. Sleep would allow some cementing of the memories as they will be hit by the background chaotic flow of current with consequent re-strengthening.

In REM sleep, the chaotic electromagnetic flow will encounter visual and other memories putting together an oftenconfused story line that are dreams. In many cases, the flow through is a once only hence the poor recall on waking of many dreams.

\subsection{Some quantitative considerations regarding synapses}

An estimate of the human brain cell number is of 100 billion $\left(10^{11}\right)$ neurons and 100 trillion $\left(10^{14}\right)$ synapses (Williams and Herrup, 1988). Since Alan Turing's use of a binary system to develop a computer, several attempts have been made to explain brain function based on computations using 0 and 1 . However, Professor Daniel C. Dennett ${ }^{3}$ has commented:

"We're beginning to come to grips with the idea that your brain is not this well-organized hierarchical control system where everything is in order, a very dramatic vision of

\footnotetext{
${ }^{3}$ University Professor, Professor of Philosophy, and Co-Director of the Center for Cognitive Studies at Tufts University.
} 


\title{
THE UNIQUENESS OF DHA WITH ITS SIX METHYLENE INTERRUPTED DOUBLE BONDS
}

\begin{abstract}
Electron density of DHA compared to the $\omega 3$ DPA. The loss of one double bond between the carboxyl and the double bond sequence is critical. The electron density peters out towards the carboxyl and the remainder of the molecule is clearly less significant. In DHA the electron profile runs throughout the whole molecule.
\end{abstract}
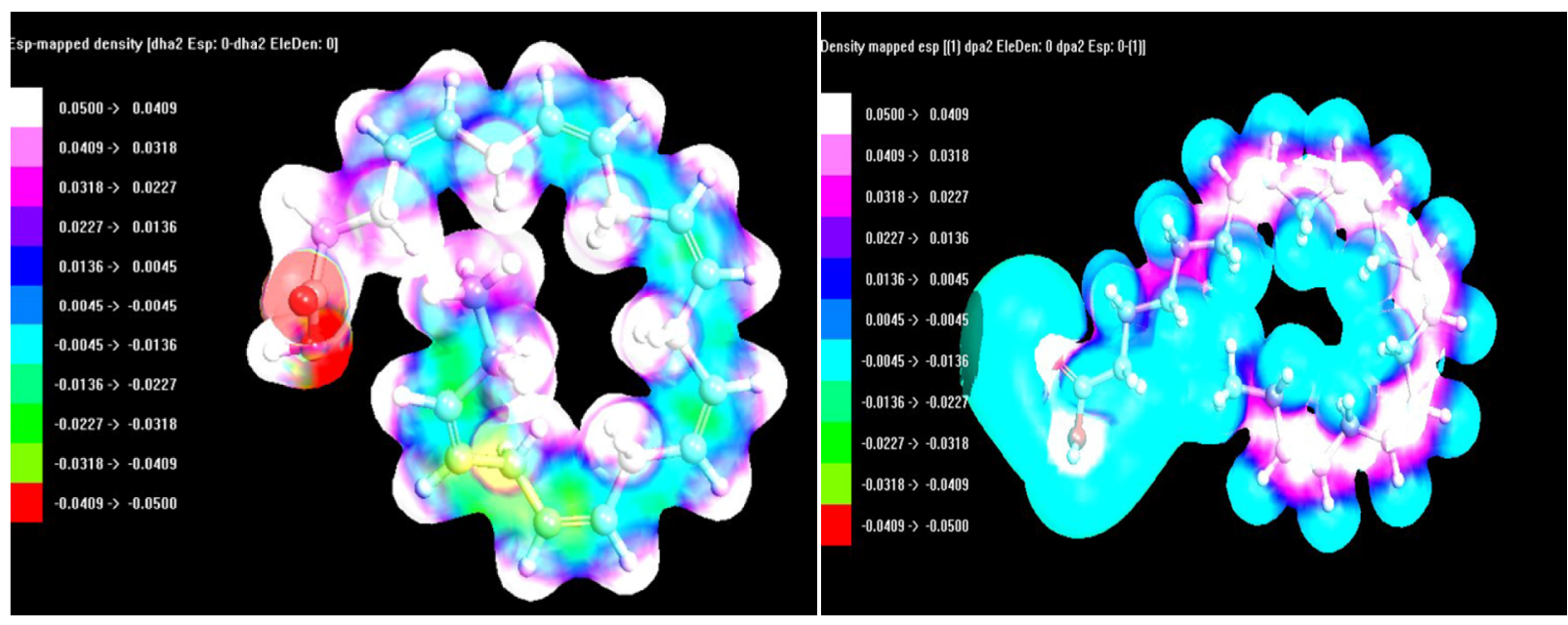

\section{DOCOSAHEXAENOIC ACID (C22:6 $\omega 3$ ) \\ DHA Neural signalling molecule}

DOCOSAPENTAENOIC ACID (C22:5 $\omega 3$ ) $\omega 3$ DPA - A precursor for DHA

Fig. 3. DHA vs DPA: The molecular modelling of the electron density for DHA is compared to that of the corresponding $\omega 3$ docosapentaenoic acid ( $\omega 3 \mathrm{DPA})$.

bureaucracy. In fact, it's much more like anarchy with some elements of democracy"

The dendrites that emerge from a neuron have up to 10000 synapses per cell. These are in-line hence a signal from a nerve cell has to travel past one then another. How then does a signal discriminate and chose only one synapse out of the very many in line? The space between neurons is filled with multiplelayers of interlocking beds of synapses in the brain. If a neuron cell dies, its axon and dendrites atrophy. Thus, one of the functions of the neuronal cell is to maintain the axons, dendrites and synapses. We suggest the synapses do not operate in line but operate as providers of electro-magnetic matrices or clouds which create the Marr type models.

\subsection{DHA versus $\omega 3-D P A$.}

There is the critical puzzle as to why DHA and not its precursor the $\omega 3$ docosapentaenoic acid ( $\omega 3$ DPA), was used in photoreception and synaptic structure over the 500600 million years of animal evolution. The $\omega 3$ DPA is a precursor for DHA therefore easier to synthesize. With one less double bond than DHA, the $\omega 3$ DPA is also less susceptible to peroxidation. Yet as far as we know, the $\omega 3$ DPA has not been used in photoreception instead of DHA. This DPA differs by only one double bond (Fig. 1). Therefore, DHA and its full six double bond sequence is unique and has to be relevant to signaling.

Gawrisch and colleagues were primarily concerned with the comparison of DHA with the $\omega 6$ docosapentaenoic acid
( $\omega 6$ DPA) which is synthesized as a replacement for DHA during $\omega 3$ deficiency. This comparison has practical implications as raised levels of the $\omega 6$ DPA were being observed in the blood of infants fed so called humanized infant formula as a marker for DHA deficiency. The humanization was largely due to the addition of $\omega 6$ linoleic acid and the question this raised centered on a concern over visual and cognitive development and function.

In so doing, Gawrisch and colleagues have so far made the best attempt at an explanation for the uniqueness of DHA. Using solid-state NMR measurements and molecular simulations they provide the image of DHA as a highly flexible molecule with rapid transitions between large numbers of conformers on the time scale from picoseconds to hundreds of nanoseconds (Gawrisch et al., 2003). They report that the low barriers to torsional rotation about $\mathrm{C}-\mathrm{C}$ bonds, which link the cis-locked double bonds with the methylene carbons between them, are responsible for this unusual flexibility. Both the amplitude and frequency of motion appears to increase towards the terminal methyl group of DHA, a point relevant to our discussion. These properties differ from what they saw in DPA $\omega 6$ DPA.

Regarding the $\omega 3$-DPA, the elasticity at $\mathrm{CH} 2$ sites and the electron density about the cis-double bond region in both $\omega 3$-DPA and DHA could be assumed to be similar in both cases. The electron density, maps ${ }^{4}$ presented in Figure 3 for each, question these assumptions. The light blue colour (middle of scale) can be

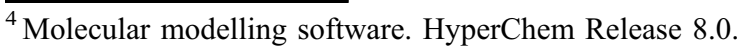


considered zero localized electron density. Immediately, one can see in $\omega 3$-DPA, the white and rose colour is focused on the $\mathrm{C}-\mathrm{C}=\mathrm{C}-\mathrm{C}$ regions which extends to the methyl end of the lipid.

In Figure 3, the light blue area and white areas are reversed in the DHA model. Localized + ve charges are on the inside [C]$\mathrm{H} 2$ and outside cis $\mathrm{H}-[\mathrm{C}=\mathrm{C}]-\mathrm{H}$ site proton sites, not the carbon sites. Further, the only site with a net negative charge [in either molecule] is the carbonyl site. Said another way, in $\omega 3$-DPA, the loss of 10 electrons from the formation of five double bonds result in a localized positive charge at $\mathrm{C}-\mathrm{C}=\mathrm{C}-\mathrm{C}$ site distributed over 18 carbon atoms (C6-C22). In DHA, the loss of 12 electrons from the formation of six double bonds instead, results in positive charge concentrated in and distributed evenly over 32 proton atoms. Further, because $12 \mathrm{H}$ sites are on the outside and seven [C]-H2 site are outside, equals 14 protons, the accounting difference between curvature inside and curvature outside is that the electron density is two higher inside than outside the DHA shape. This can account for the net negative charge calculated at the carbonyl site.

The electron density is also not exactly uniform among the double bonds of DHA: green occurs more strongly towards the carbonyl end of the molecule, i.e. in each $\mathrm{CH} 2-(\mathrm{H}-\mathrm{Ca}=\mathrm{Cb}-$ $\mathrm{H})-\mathrm{CH} 2$ moiety, an electron density gradient is possible from $\mathrm{Ca}$ to $\mathrm{Cb}$ : the $\pi$-electron cloud is leaning.

In the electron density map, molecular forces on all $\mathrm{CH} 2$ sites of DHA will be equal. Raman spectroscopy told us that $\mathrm{C}-\mathrm{C}=\mathrm{C}-\mathrm{H}$ in plane rocking happens to equal $\mathrm{C}=\mathrm{C}-\mathrm{C}-\mathrm{H}$ in plane rocking (the former a cis $\mathrm{H}-\mathrm{H}$ conformation, the latter a trans $\mathrm{H}-\mathrm{H}$ orientation), three of the four $-\mathrm{CH}$ sites will be identical, and the fourth i.e. the out of plane $\mathrm{C}-\mathrm{H}$ is a cause of the curvature (Broadhurst et al., 2017).

Because in the DPA, the electron density is higher in the $\mathrm{C}-\mathrm{C}=\mathrm{C}-\mathrm{C}$ moieties, the $\mathrm{H}$ sites transitions could be more transient and less influenced by its lipid [membrane] environment. In DHA, its conformation can be influenced by its lipid [membrane] environment. In DHA, the $\mathrm{C}$ backbone is neutral and the $\mathrm{H}$ atoms carry a positive electron density. That is, the electron density maps of the molecules are quite different. The influx to DHA of a negative current from an external source, i.e. a photon or energy of a potential difference across the membrane, would plausibly result in the flow of an electro-magnetic current. We discuss later how the energy of the current would in DHA, be under precise control by the Pauli Exclusion Principle.

In evolutionary terms, neural signaling starts in an $\omega 3$ rich environment some 600 million years ago ahead of the Cambrian Explosion of the phyla we have today. The extreme conservation of DHA in signaling systems since then, suggests DHA has an important role to play here and the full six methylene interrupted double bonds are critical.

\subsection{Quantum mechanics}

Where double bonds are conjugated in a molecule, the $\pi$-electron clouds overlap and a current can flow across the molecule as in a copper wire. In DHA, methylene groups $(-\mathrm{CH} 2-)$ separate the double bonds. In classical physics, methylene interruption $(-\mathrm{CH}=\mathrm{CH}-\mathbf{C H 2}-\mathrm{CH}=\mathrm{CH}-)$ presents a barrier confining the electrons to their respective wells. That is DHA in the top and bottom of the neuronal, synaptic or

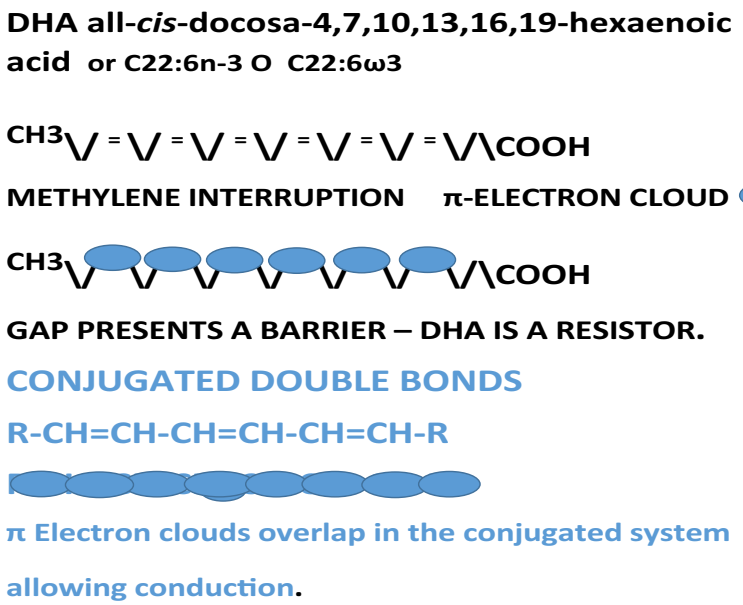

Fig. 4. Double bonds: A depiction of the comparison between potential for electron conductivity in conjugated double bonds compared to the methylene interrupted double bonds of DHA. The overlapping $\pi$-electrons clouds in the conjugated set (e.g. in retinal) overlap allowing the electrons to flow freely in response to a potential difference. The methylene groups separating the double bonds in DHA localise the electrons.

photoreceptor membrane is a resistor. That is, these DHA rich membranes would be resistors (see Fig. 4).

Under certain conditions however, the $\pi$-electrons can be persuaded to flow somewhat like a semi-conductor. We propose that the six-methylene interrupted double bonds of docosahexaenoic acid can provide a mechanism in this manner, for $\pi$-electron participation in the signaling process (see Fig. 5).

We do not offer exclusivity to DHA in this matter but as it is so rich in the photoreceptor, neuronal and synaptic membranes it is clearly a principle game player.

\subsection{The Heisenberg uncertainty principle}

We started with the Clarke-Maxwell concept of induction. The properties of electromagnetic waves in classical physics tell us that the movement of a magnetic field will induce the flow of electrons in a conducting material. Magnetic and electric fields are completely superposable. That is if field B1 is generated by current I1, and in another circuit current I2 generates field $\mathrm{B} 2$, then the magnetic field generated is the sum of $\mathrm{B} 1$ and $\mathrm{B} 2$. This principle operating with the cohesion of electromagnetic waves in the circuits of the brain offer the imagination a feast of possibilities for communication and a mechanism for the brain to recognize an event. The brain recognizes electricity.

In quantum mechanics, the electron has the dual properties as a particle and a wave. As a particle, it cannot penetrate methylene barrier that separates the double bonds. The Heisenberg uncertainty principle means there is no knowing where the wave begins and ends. Indeed, Richard Feynman would have said that there is a probability that the electron could be anywhere, and all possibilities have to be considered. 
ELECTRON TUNELLING: THE DUAL PROPERTIES OF THE ELECTRON CONFERRING ABSOLUTE PRECISION TO THE SIGNAL

A quantum mechanical explanation for $600 \mathrm{my}$ exclusive use in neural signalling. $\delta[-\mathrm{VE}]$ $\delta[+\mathrm{VE}]$

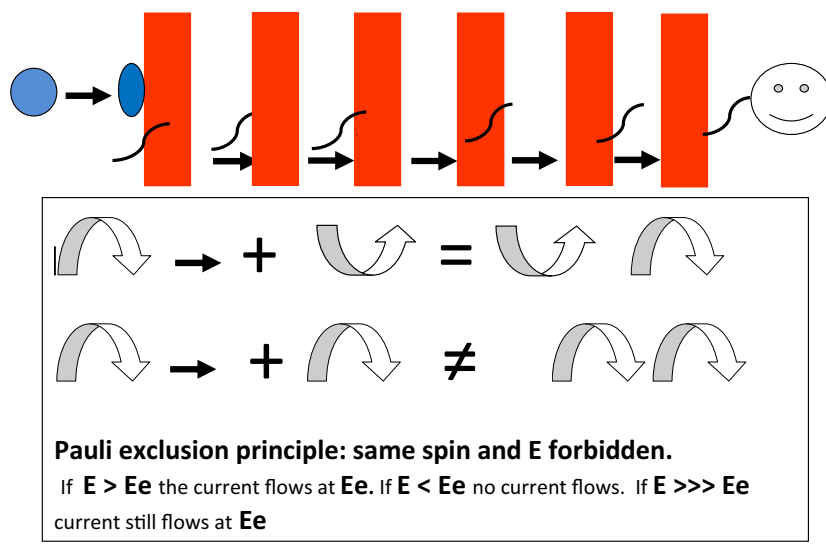

Taken from Crawford et al (1)

Fig. 5. Precision of the signal: The figure illustrates the possibility of electrons tunneling through the so-called energy barrier. They can only flow at one energy level.

As a wave form, the electron can penetrate the so called, barrier and pop up the other side. If it meets an electron, there with the same quantum mechanical properties it cannot stay. If on the other hand, an electron has been removed leaving a hole, then an electron can occupy the hole but only and only if it has the same identical properties of the removed electron. In this way, a current can flow governed by the Pauli Exclusion Principle. That current can only be at the precise energy level of the electron removed. We now have an answer to the puzzle as to the need for absolute precision of the signal.

Hopfield (1974) described this process of electron transfer in proteins whereby electrons could tunnel through the barriers. He calculated the distances over which tunneling could occur. In terms of the electron tunneling (ET) proposed here.

Hopfield (1974) calculated that the limit was about an $8 \AA$ edge to edge distance between ET parameters. The distance in methylene interruption is just less than $6 \AA$ making the ET transfer between the $\pi$-orbitals feasible throughout the DHA molecule. The possibility fails if one double bond is removed and replaced by a saturated chain as in the DPAs. The possibility of finding an electron distant from its usual orbital falls off exponentially with distance. Whilst tunneling is feasible across the length of DHA, it is not so plausible if one double bond is removed (see Fig. 5).

Tunneling as a plausible mechanism would explain three currently unexplained phenomena:

- how is the system capable of responding over a range of $1-10000$ ?

- why does activation with a single photon always produce an identical response, regardless of the energy input, which is unexpected in classical theory?

- how is the precision of the signal guaranteed?

\subsection{The Pauli exclusion principle and precision of the signal}

Tunneling explains all three points. The electrons will only jump underneath the energy barrier, from one well to the next at a precise energy level $\mathrm{El}$ and no other. If in the photoreceptor, you increase the photon input the energy level can rise above and if $\mathrm{E} 2>\mathrm{El}$ or $\mathrm{E} 3>>\mathrm{El}$ the electrons still go through at El. At an energy level of $<\mathrm{E} 1$ nothing will happen. If E3 was very large, one might expect an "after glow" or image but the signal will be at E1. Here is a mechanism for depolarizing the membrane at a precise energy level. (see Fig. 5).

Following our hypothesis that DHA is central to signaling, the photoreceptor could be considered as a synapse with the outside world of photons. Its function is to respond with high precision to the incoming signal as explained earlier. It is difficult to deplete the photoreceptor of DHA, the high concentration of which, is powerfully protected. Nonetheless, loss of DHA in deficiency in the experiments of Belkonen, Maude and Anderson (Benolken et al., 1973), Neuringer et al. (1984) and in infants, Birch et al. (2010) consistently, illustrated a loss of conductivity and loss of visual acuity with a deficiency of DHA.

Bear in mind nature often has more than one means of affecting a critical function. The involvement of DHA in depolarization could operate with the presently accepted ionic movement and the G-protein activity.

Note that a large part of the energy consumption by the brain is used by the synapses (Harris et al., 2012), a high proportion of which will be consumed by pushing ionic movement against a concentration gradient. The consequence is the establishment of a potential difference. The discharge or depolarization is the signal which we propose is an electrical discharge through DHA.

The view of many configurations of the molecule rapidly changing shape is taken from measurements implying shape changes in pico-seconds. There will be optimal configurations for electron transport, but little is known about the influence of a potential difference across the membrane on these changes. In our 2013 paper (Crawford et al., 2013), we calculated that at least one energy band exists in DHA and for our purposes, one band is all that is needed. The quantum mechanical treatment however, provides an explanation in electron tunneling of signal precision not inherent in classical physics and not explained by theories based on proteins (Fig. 5).

\subsection{The photo-receptor versus the synapse}

In summary: let us suppose that DHA is the conduit for electrons to flow at a precise energy level and specific wave form, generated by electron tunneling. This then would be the enactment of a neural pathway, learnt by repeated activation with DHA bio-magnification. The enhanced levels leading to enhanced density of the $\pi$-electron field, protein synthesis and hence a neural path. Protein provides the energy.

The inner cell membrane is the richest in DHA. The ethanolamine phosphoglyceride in the neuron holds about $20-30 \%$ DHA, the synapse $18-32 \%$ and the photo receptor 
greater than $50 \%$. These data are approximate as analysis mostly done contain a mixture of different cell types; there are also brain, regional differences (Diau et al., 2005).

In the photo receptor, all phosphoglyceride SN2 positions contain DHA and some include DHA in the SN1 position, which is most unusual. It can be said that the photo receptor is fully saturated with DHA and hence is operating at full potential: you cannot get any more DHA into the receptor membrane.

In the photoreceptor operating at full potential there is no concept of learning. It has to respond immediately and fully to first and subsequent light. On the other hand, synapses in the brain do not have this total, non-stop activation and responsive signaling of the photoreceptor. However, they do possess the property of selectively incorporating DHA with high specificity (Rodriguez de Turco et al., 1999). During use, synapses like the photoreceptors break down and are remodeled. On average the synapse membrane inner lipids might contain 18-36\% DHA. However, there is room for a lot more.

Our proposition is that the input from a sensory organ such as vision or hearing, establishes a matrix of strengthened and hence, learnt neurons and synapses, which if repeated enough times is enriched in DHA and proteins. The $\pi$-electrons of the DHA then provide for the memory or neural pathway with a signal precision guaranteed by the electron tunneling and Pauli Exclusion Principle. It is accepted that the enrichment of synapses represents our memories. In our thesis we refer to a multi-dimensional electromagnetic cluster or matrix based on the enhanced density of DHA's $\pi$-electrons. On activation, the matrix will light up and vanish at a precise energy level defined by the semi-conduction properties of DHA.

An interesting recent paper from the Blue Brain Project lends some support to this idea (Reimann et al., 2017). In their introduction, the authors point out that the lack of a link between what we know of structure and its function has hampered progress. They then write: "We have now come closer to describing such a link by taking the direction of synaptic transmission into account, constructing graphs of a network that reflect the direction of information flow...". This has "revealed a remarkably intricate and previously unseen topology of synaptic connectivity". In this paper they refer to cliques, which would be our David Marr type matrices. The brain, they claim, processes information by "forming increasingly complex functional cliques and cavities." This is similar to our thesis except we offer electromagnetics and the quantum mechanical principles of the six, methylene interrupted double bonds of DHA as the mechanism for information flow with depolarization effected with the allimportant precision of the signal.

\subsection{Summary of chaos theory in sleep and wakefulness}

The chaotic but constant flow of electrons can pick up memories by entering one pathway or another. For example, we can see basic brain function as follows:

- AWAKE: Chaotic flow of electro-magnetic waves hit a memory and become deterministic which can be modified by sensory input from the real world. Hence the random thoughts that occur continuously unless we are following a line of learnt information or construction of thoughts in say poetry, writing or designing.
- LPT: During deep sleep, long term memories will be refreshed by the chaotic electron flow.

- REM SLEEP: Chaotic flow of weak electro-magnetic waves with no external modification hits odd memories and gives wild, perhaps crazy memory based imagery we call dreams. In REM sleep the chaotic assault of electrons can settle on a random memory or activate several images or memories, resulting in a sense or no-sense dream. If this is a one-time event it will be difficult to recall. Recurrent strikes activating the same imagery/dream can be recalled because the course taken mimics the learning process.

- RECALL - ASSOCIATION -NAMES: Electromagnetic waves synchronise like the harmonics inducing a current flow. Recalling A connected to B results in electromagnetic waves the energy of which is equal to $\mathrm{A}+\mathrm{B}$. The sum will be greater than the background, resulting in a higher level of impact felt by the brain and hence eureka.

\subsection{Is the brain a musician?}

The synchronization of two or more linked memories, could be considered like the harmonic that occurs when you strike a note on a piano with the loud pedal depressed. Other strings vibrate. The resultant harmonics are a positive integer multiple of the frequency of the original wave-length. For example, when a face is seen, the activation of the memory results in electromagnetic wave forms with at least one of which strikes a harmonic in the memory of the name which begins to vibrate so to speak and adds to the electron flow of the face. The enhanced flow of electrons is then felt by the brain which is recall and recognition.

This proposal is similar to John Hagelin's view of vibrations in an elastic band within which there are many different frequencies. This harmony may be behind our love of music and indeed the appreciation of the notes being in a fixed set of wave length intervals. If violin or piano string is out of tune it is soon noticed. In some respects, one could consider the brain as a musician. It is interesting that it is easier to learn a song than a poem. Although many explanations can be put forward for this apparent facility, the ability to identify the type of musical instrument which is making a sound, the ease of recalling a melody or an out of tune instrument is consistent with the concept of induced electromagnetic flow based on harmonics.

It is the lipid not the protein which is providing for function and the wave like property of the electrons, implicit in ET as a wave, which offer both the precision of the signal and ability to make harmonic connections between memories. That ability is of course the basis of cognition.

Gerardo Adesso, Associate Professor at the University of Nottingham in the UK, with coauthors from Spain and India, have shown that "coherence and entanglement are quantitatively, or operationally, equivalent, based on their behavior arising from their respective resource theories." Electron wave harmonics with entanglement and cohesion gives us a mechanism for the fast, association of memories, which provide for cognition and the basic functions of the human brain ${ }^{5}$.

${ }^{5}$ http://phys.org/news/2015-06-physicists-quantum-coherence-entan glement-sides.html\#jCp. 

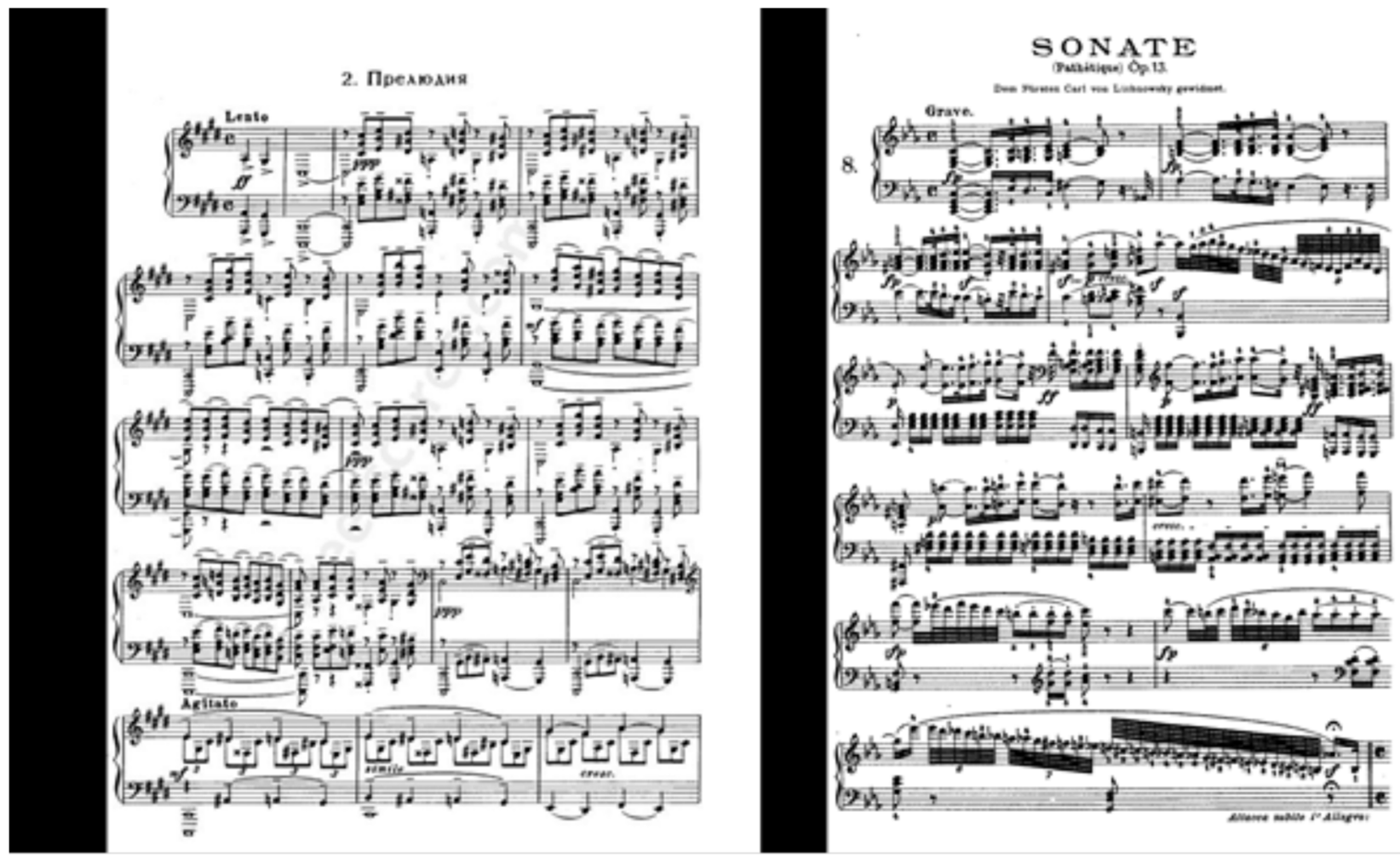

Fig. 6. Music is composed of notes. Each note is a specific wave length and is played with a specified energy. Each cord is heard as one. The communication of sound to the brain is as wave forms. Photon-reception is also received as wave forms. We propose transduction results in electron wave forms utilizing the $\pi$-electrons to ensure precision of the signal. The complexity of a visual scene might be thought of as represented in the brain as a complex of wave forms, imagines like a sheet of music with the whole page played as one instant of vision. This image of how the brain sees the real world is like the concept described by David Marr (Merzenich et al., 2014; Marr, 1982).

Is there electron cohesion/entanglement at work ${ }^{6}$ The laborious movement of sodium with its large coating of water of hydration, does not seem to fit with the speed of the imagery of the working brain. Or is it the cohesion of discreet, part frequencies sufficient to explain recall as for an example the recall of a name when the image of the face from the retina is activated. This behaviour, could be the basis of such near instantaneous perception and interpretation of external information.

Quantum coherence and quantum entanglement are imbedded in superposition. Funnily enough what we propose is quite like the Penrose-Hammerhoff position when they suggest consciousness arising from quantum vibrations inside the brain's neuron and with vibrations which interfere, 'collapse' and resonate across scale, control neuronal firings, generate consciousness, and connect ultimately to 'deeper order' ripples in space-time geometry. The difference is that we have identified a candidate for electromagnetic behaviour/vibrations (frequencies) in the lipid rather than the protein. Moreover, it is likely the involvement of DHA $\pi$-electrons operating through the tunneling principle which offers the solution to the requirement for absolute precision guaranteed by the Pauli Exclusion Principle and not explained by theories based on the proteins.

\footnotetext{
${ }^{6}$ http://phys.org/news/2015-06-physicists-quantum-coherence-entan glement-sides.html\#inlRlv.
}

Is the brain a musician? One can consider the transduction of the shower of photons bombarding the retina. We have discussed how the photoreceptor facing the wrong way ensures the entry of photons as waves. The great galaxy of colours which make up one page of vision, are converted into electrons. Above we describe how the $\pi$-electrons of DHA worked as wave forms. If the transduction of photons is as wave forms, it is reasonable to consider the onward transfer as a wave form. That is, the image as seen by the retina is formed by an electron version of the original photon input.

This concept is analogous to cords in music. For example, play the $\mathrm{C}$ major cord on the piano and you hear a bright, happy sound which is the merge of all four notes. Play the $\mathrm{C}$ minor cord and the sound is somber. Yet the notes are the same except the $\mathrm{E}$ is half a tone shifted to $\mathrm{E}$ flat and this radically changes the perception of the sound. In both cases, all four notes are heard as one sound.

The opening cord in the third bar of Rachmaninov's Prelude in C Sharp Minor is quite distinct but has the same somber mood of the opening cord of Beethoven's Pathetique Sonata. On hearing the Beethoven cord, a pianist might recognize it and what comes next. The first three notes of the Prelude would certainly result in a flow of music in the mind.

The brain indeed has a remarkable ability to retain musical information. Daniel Barenboim on one occasion played all 5 Beethoven piano concertos on two consecutive evenings at the Royal Albert Hall in London. He had no music. The amount of 


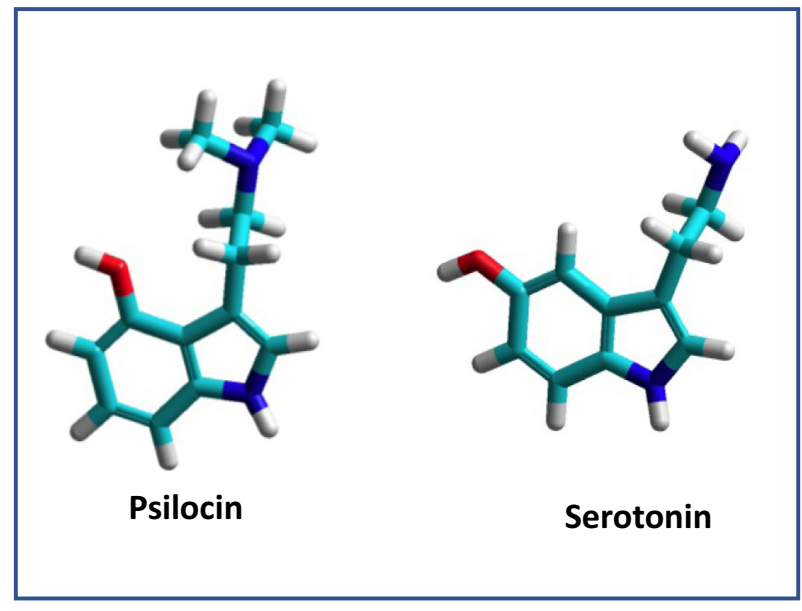

Light blue $\mathbf{C}$; dark blue $\mathbf{N}$; red $\mathbf{O}$; white $\mathbf{H}$

Fig. 7. Psilocin and serotonin: comparison of the structures. Both are zwitterions.

information stored to achieve that feat is staggering. Barenboim would doubtless argue that playing from memory is superior because the brain is free to interpret each note and phrase of the music to be appropriate for the occasion.

Look at the two pages of music in Figure 6. Each note is a wave. As written, it is of course a longitudinal affair. However, the score helps the imagination comprehend how the brain might be handling information. Waves of photons elicit waves of electrons. These then create the image made up of the electron waves mimicking the incoming photos at that instant. It is like the page of music but condensed into an instant, a pixel if you like.

The brain's love of music is inherent in every culture and in our own heads. The "Ear Worm" which frequently causes a tune, song, or even an orchestral piece to jump into our thoughts is perhaps an example of this notion of the brain as a musician.

Figure 8 gives an image of the way in which vision or other sensory, quantum of input could be represented in the brain. With the range of electromagnetic waves being so large, the possibilities would be in a very high order of magnitude and very difficult if not impossible to compute. This view coincides with the view of Hammerhoff and Penrose who claim brain function to be non-computable (Hameroff and Penrose, 1998, 2014). Indeed, their hypothesis, although based on protein tubules, is similar to ours. Based on quantum mechanics it is possible to embrace precision of the signal which is essential yet so seldom discussed. We are of course suggesting it is the lipids not the protein that is the key to function.

\subsection{Perception - not only DHA}

The concept of perception is different to memory but may use memory to make cognition out of it. In his book on the experience of mescaline Aldus Huxley writes of the heightened perception on seeing the leg of a chair or a flower in the garden (Fig. 7). The leg of the chair becomes almost all pervading in his mind (Huxley, 1954).

Molecules other than DHA are theoretically also capable of participating in ET and a case in point is serotonin (5-hydroxytryptamine $5 \mathrm{HT}$ ) and the remarkable apparent heightening of

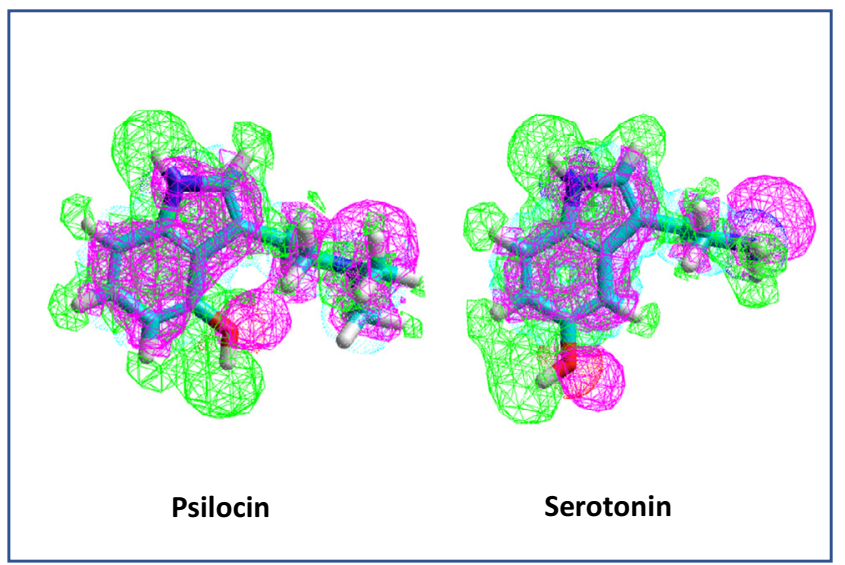

Light green: positive electron density; red-violet: negative electron density

Fig. 8. Comparison of psilocin and serotonin Electron Density Maps. In psilocin the sites of negative electron density at the side chain nitrogen and the ring oxygen are closer together than in serotonin; there would be a greater probability of electron transfer at a receptor site, tunneling via the shorter pathway between the ring $-\mathrm{OH}$ and side chain $\mathrm{N}$. The strongest acidic $\mathrm{pKa}$ for serotonin is 2.15 and its reactivity is $58.18 \mathrm{~m}^{3} \mathrm{~mol}^{-1}$, Whereas for psilocin the strongest acidic $\mathrm{pKa}$ is 8.97 with a reactivity of $62.42 \mathrm{~m}^{3} \mathrm{~mol}^{-1}$ reflecting influence of the tertiary compared to the primary amine and the shift of the hydroxyl ${ }^{7}$. Whilst the possibility of direct electron transfer might be considered depending molecular motion, tunneling in each of these structures would, like in DHA, occur at its unique energy level.

perception by its antagonist psilocin. Serotonin is considered to control mood, appetite, and sleep. It has also been connected with some cognitive functions, including memory and learning. Modulation of serotonin function at its synaptic receptors is thought to be a major action of several classes of pharmacological antidepressants.

Studies on entheogens seem to imply decrease total brain activity, yet with an increase of variability in brain activity. However, for the patient, as with Aldus Huxley, there is a seemingly vastly increase in the perceived brain activity.

Psilocin has been shown in studies to generate hyperconnectivity between neurons in places that "coincidentally" do not usually form connections. The molecular similarity of psilocin and serotonin is remarkable, and some would say this is why psilocin works. However, the idea that psilocin blocks serotonin does not seem to fit with the great enhancement of mood and so-called perception - a heightening of the properties of serotonin.

The major differences in molecular structure are the primary amine of serotonin $\left(-\mathrm{NH}_{2}\right)$ replaced by a tertiary amine $\left(-\mathrm{N}-\left(\mathrm{CH}_{3}\right)_{2}\right)$. The latter has a much stronger positive nature. The negative hydroxyl group in serotonin is 6 carbons removed from the nitrogen compared to 5 for psilocin. The initial distance is covered by a conjugated group but the last two are methylene groups creating a barrier to electron transfer except by tunneling. The probability of ET in psilocin is consequently much greater than in serotonin as is seen in the structures above.

\footnotetext{
${ }^{7}$ http://www.t3db.ca/toxins/T3D2458psilocin, http://www.t3db.ca/ toxins/T3D4298serotonin.
} 


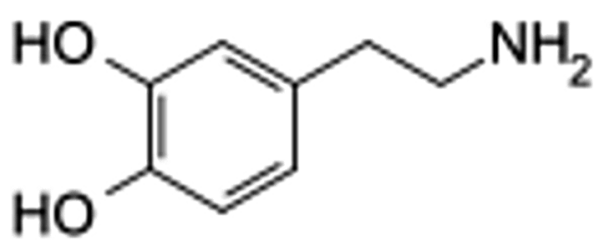

Fig. 9. Has dopamine a similar potential for controlled electron transfer as a component of its activity?

The spin density in serotonin has four sites green, three sites pink and one site in an alpha position to the indole $\mathrm{NH}$ being half pink, half green. In Psilocin (left hand molecule), four sites are green, four are pink and the actual location of green and pink are OPPOSITE: green in serotonin pink in psilocin! Pink corresponds to higher electron density, green lower electron density.

The question is does psilocin allow greater electron transfer (see Fig. 8) hence leading to what appears to be heightened perception whereby the sight of a chair or a flower consumes the mind and responsiveness to other matters sink giving the chair or flower an extraordinary presence.

Looking at the two molecules and the similarity with psilocin clearly more potentially electrically active, it is difficult to avoid the conclusion that the apparent heightened perception is due to enhanced electron transfer. It could then be argued that the psilocin is flooding the brain which would dampen other functions giving the feeling of enhanced perception when in reality, it is reduced perception.

A review of psilocybin for treatment-resistant depression (Carhart-Harris et al., 2017) explains that there is there is a growing body of evidence that "enhanced 5-HT2AR signalling produces a plastic state (in the sense of an enhanced capacity for change)". It has been commented previously (Andrade, 2011) that in neurotransmission, the principal effect of serotonin in binding to the 5-HT2AR is "to increase the excitability of the host neuron. The receptor 5-HT2AR is the main excitatory GPCR of the serotonin receptor family with activation causing a depolarising (excitatory) effect)"(Carhart-Harris et al., 2017).

These example may be one of many and indeed suggests to us that DHA will not be the only molecule involved in sharing electromagnetic waves. Dopamine for example might also be a candidate for participating in ET and current energy control (Fig. 9).

It has an electrochemical profile and potential for ET like serotonin and is involved in cognition, some aspects of motor, arousal, control and reward. Being associated with different receptors it could direct electron waves in a different manner.

Our approach here is of a very simplistic nature. It seems to us highly unlikely that in face of the classical $\mathrm{HH}$ potential differences across the membrane that all these $\pi$-electrons will simply ignore the potential difference. Our hypothesis is put forward in our hope it will stimulate others to challenge or extend the electromagnetic field principles of electrons and brain function outlined in this paper.

\section{Summary}

We propose the synapses are an effective sea of DHA's $\pi$-electrons. Other molecules with similar properties are likely to participate. However, the 500-600 million years of evolutionary history of DHA being exclusively used in photo receptors, synapses and neurons for their signaling membrane structures is a compelling argument for the absolute essentiality for DHA in signaling. The capability of the synapses forming matrices representing the real world is several orders of magnitude more likely as a formative than the neurons themselves which care for the axons, dendrites and synapses and act as conduits. We propose DHA is the prime candidate for electron wave movement but only via electron tunneling which provide precision to incoming sensory and for neural pathways.

The classical explanation or ion swapping, protein synthesis. DNA and RNA participation and indeed protein synthesis to strengthen synapses, offer no sense of the precision required for vision, hearing, recall, or the behaviour of neural pathways. DHA and quantum mechanical poetries of $\pi$-electron tunneling provide that precision and moreover do so with electrons as waves. We postulate that the vibrations of the waves, cohesion and entanglement can explain the associations required for memory, recall and cognition.

The EEG tells us that waves of electrons are flowing through the brain. Hence there is chaotic stimuli, which will become deterministic on encountering this or that neural pathway leading to random thought, which in the awake state is tempered by continuous sensory input. Its constant flow is also at the core of all consciousness and function.

The brain feels pain, hot and cold etc., delivered to it but has no pain receptors itself. In the thought process it feels the successful transfer of electron waves through the harmony and cohesion amplifying the wave flows consequent on making correct associations.

In REM sleep the same is happening but the chaos in the system picks up random memories or association which when put together make up a dream that may well be nonsense. In the awake state, a chaotic flow can energize a random memory resulting in a thought -we are seldom truly thoughtless. That the brain responds to and feels electricity is well known.

If this thesis proves to be correct, it will open new doors to drug design and therapy. It will establish without any doubt (although hardly needed) the pivotal role of docosahexaenoic acid in the signaling structures of the brain and hence its nutritional importance to intelligence and mental health. With the continuing rise in mental ill-health this recognition of essentiality in the food web has a special significance. It may also give an insight to the question of Hammerhoff and Penrose as to the possibility that a new physics is operating in the brain and just what is that new physics?

Being aware of the complexity of this subject we offer this theory of brain function for further discussion.

Acknowledgements. We wish to express our appreciation for financial support underpinning the observations on DHA from the Mother and Child Foundation, the Waterloo Foundation, and from the late Professor Letten F Saugstad for her constant questioning of what DHA was doing in the brain, together with support from her Letten Foundation, as well as the late Professor Cedric Hassall FRS for his mentoring. We thank the Waterloo Foundation, and Wellohi for finance to help in the writing of this paper, Stephen Cunnane and Samuel Levine for prompting and encouragement. We also thank The Société Française pour l'Étude des Lipides, Bernadette 
Delplanque and her colleagues for continuing support for lipid research and the Medale Chevreul.

\section{References}

Andrade R. 2011. Serotonergic regulation of neuronal excitability in the prefrontal cortex. Neuropharmacology 61: 382-386.

Benolken RM, Anderson RE, Wheeler TG. 1973. Membrane fatty acids associated with the electrical response in visual excitation. Science 182(118): 1253-1254.

Birch EE, Carlson SE, Hoffman DR, et al. 2010. The DIAMOND (DHA Intake And Measurement Of Neural Development) study: a double-masked, randomized controlled clinical trial of the maturation of infant visual acuity as a function of the dietary level of docosahexaenoic acid. Am J Clin Nutr 91(4): 848-859.

Bloom M, Linseisen F, Lloyd-Smith J, Crawford MA. 1999. Insights from NMR on the functional role of polyunsaturated lipids in the brain. In : Maraviglia B, ed. Magnetic resonance and brain function - Approaches from Physics Proceedings of the 1998 Enrico Fermi International School of Physics, Varenna (Italy): Enrico Fermi Lecture, Course \#139, pp. 1-27.

Broadhurst CL, Schmidt WT, Nguyena JK, et al. 2017. Continuous gradient temperature Raman spectroscopy and differential scanning calorimetry of N-3DPA and DHA from $100^{\circ}$ to $10^{\circ} \mathrm{C}$. J Chemphyslip 03.002 0009-3084.

Carhart-Harris RL, Roseman L, Bolstridge Mark, et al. 2017. Psilocybin for treatment-resistant depression: fMRI-measured brain mechanisms. Scientific Reports 7: 13187. DOI: 10.1038/ s41598-017-13282-7.

Chawla A, Repa JJ, Evans RM, Mangelsdorf DJ. 2001. Nuclear receptors and lipid physiology: opening the X-files. Science 294: 1866-1870.

Crawford MA, Hassam AG, Williams G, Whitehouse WL. 1976. Essential fatty acids and fetal brain growth. LANCET i: 452-453.

Crawford MA, Thabet M, Wang Y. 2018. An introduction to a theory on the role of $\pi$-electrons of docosahexaenoic acid in brain function. OCL. DOI: 10.1051/ocl/2018010.

Crawford MA, Broadhurst CL, Guest M, et al. 2013. A quantum theory for the irreplaceable role of docosahexaenoic acid in neural cell signaling throughout evolution. Prostaglandins Leukot Essent Fatty Acids (PLEFA) 88(1): 5-13. DOI: 10.1016/j.plefa. 2012.08.005. PMID: 23206328.

Diau G-Y, Hsieh AT, Sarkadi-Nagy EA, et al. 2005. The influence on long chain polyunsaturate supplementation on docosahexaenoic acid and arachidonic acid in baboon neonate central nervous system. BMC Medicine 3: 11

Gawrisch K, Eldho NV, Holte LL. 2003. The structure of DHA in phospholipid membranes. Lipids 38(4): 445-452.

Hameroff S, Penrose R. 1998. Quantum computation in brain microtubules The Penrose- Hameroff 'Orch OR' model of consciousness, Phil Trans R Soc Lond A 356: 1869-1896.

Hameroff S, Penrose R. 2014. Consciousness in the universe: a review of the 'Orch OR' theory. Phys Life Rev 11(1): 39-78. DOI: 10.1016/j.plrev.2013.08.002. Epub 2013. PMID: 24070914
Harris JJ, Jolivet R, Attwell D. 2012. Synaptic energy use and supply. DOI: 10.1016/j.neuron.2012.08.019.

Hopfield JJ. 1974. Electron transfer between biological molecules by thermally activated tunneling. Proceedings of the National Academy of Sciences USA 71: 3640-3644.

Huxley A. 1954. The doors of perception, (The Gates of Heaven and Hell), London: Chatto and Windus.

Kitajka K, Sinclair AJ, Weisinger RS, et al. 2004. Effects of dietary $\omega-3$ polyunsaturated fatty acids on brain gene expression. Proc Natl Acad Sci USA 101(30): 10931-10936.

Marr D. 1982. Vision: a computational investigation into the human representation and processing of visual information, vol. XVII. San Francisco, CA: W. H. Freeman.

Merzenich MM, Van Vleet TM, Nahum M. 2014. Brain plasticitybased therapeutics. Front Hum Neurosci 8(385): 1-16.

Neuringer M, Connor WE, Van Petten C, Barstad L. 1984. Dietary $\omega-3$ fatty acid deficiency and visual loss in infant rhesus monkeys. $J$ Clin Invest 73(1):272-276.

O'Reilly EJ, Olaya-Castro A. 2014. Non-classicality of the molecular vibrations assisting exciton energy transfer at room temperature. Nat Commun 5: 3012. DOI: 10.1038/ncomms4012. PMID: 24402469

Purdon AD, Rapoport SI. 2007. Energy consumption by phospholipid metabolism in mammalian brain. In : Gibsson G, Dienelm G, eds. Handbook of Neurochemistry and Molecular Neurobiology. New York (USA): Springer, pp. 401-427.

Reimann MW, Nolte M, Scolamiero M, et al. 2017. Cliques of neurons bound into cavities provide a missing link between structure and function. Front Comput Neurosci 11: 48. DOI: 10.3389/fncom.2017.00048.

Rodriguez de Turco EB, Parkins N, Ershov AV, Bazan NG. 1999. Selective retinal pigment epithelial cell lipid metabolism and remodeling conserves photoreceptor docosahexaenoic acid following phagocytosis. J Neurosci Res 57(4): 479-486.

Scholes GD, Fleming GR, Chen LX, et al. 2017. Using coherence to enhance function in chemical and biophysical systems. Nature 543(7647): 647-656. DOI: 10.1038/nature21425.

Suzuki H, Manabe S, Wada O, Crawford MA. 1997. Rapid incorporation of docosahexaenoic acid from dietary sources into brain microsomal, synaptosomal and mitochondrial membranes in adult mice. Internat $J$ Vit Res 67: 272-278.

Valk SL, Bernhardt BC, Trautwein FM, et al. 2017. Structural plasticity of the social brain: differential change after socioaffective and cognitive mental training. Sci Adv 3(10): e1700489. DOI: $10.1126 /$ sciadv.1700489.

Williams RW, Herrup K. 1988. The control of neuron number. Ann Rev Neurosci 11(1): 423-453. DOI: 10.1146/annurev.ne. 11.030188.002231. PMID 3284447.

Willshaw DJ, Dayan P, Morris RGM. 1971. Memory, modelling and Marr: a commentary on Marr 'Simple memory: a theory of archicortex'. Phil Trans $R$ Soc B 370: 20140383.

Woollett K, Maguire EA. 2011. Acquiring "the Knowledge" of London's layout drives structural brain changes. Curr Biol 21 (24-2): 2109-2114. DOI: 10.1016/j.cub.2011.11.018. PMCID: PMC3268356.

Cite this article as: Crawford M, Thabet M, Wang Y, Broadhurst C, Schmidt W. 2018. A theory on the role of $\pi$-electrons of docosahexaenoic acid in brain function. OCL 25(4): A403. 